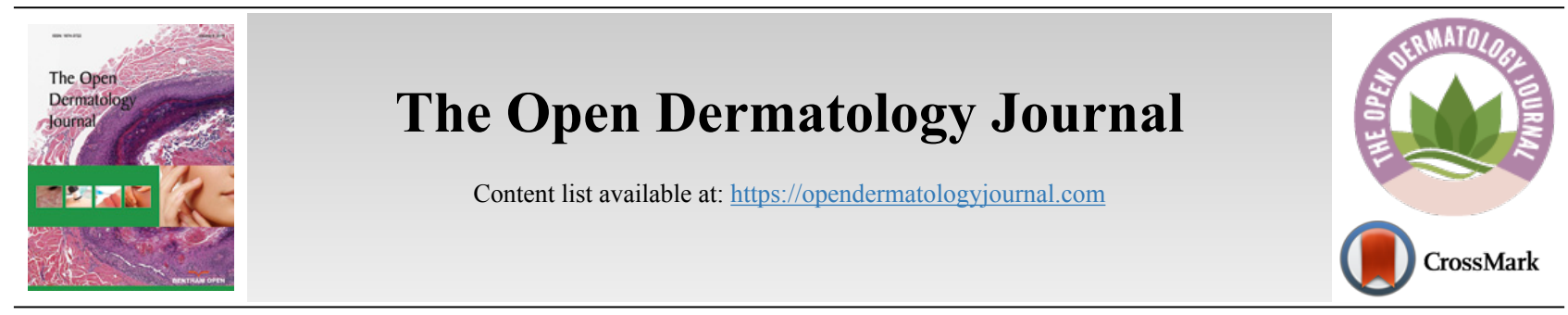

RESEARCH ARTICLE

\title{
Assessment of Vitamin D Status Among Cases with Pityriasis Alba
}

\author{
Wisam Majeed Kattoof ${ }^{1, *}$ and Ahmed Abdulhussein Kawen ${ }^{2}$ \\ ${ }^{\prime}$ AL-Mustansiriyah University/College of Medicine, FICMS Dermatology and Venerology, Baghdad, Iraq \\ ${ }^{2}$ University of ThiQar/College of Medicine, FICMS Dermatology and Venereology, Nasiriyah, Dhi Qar, Iraq
}

\begin{abstract}
:
Background:

Pityriasis alba, is a common benign skin disease occurring predominantly among children, often on their face. Clinically, the spots of pityriasis alba are off-white in color, round with poorly defined margins that bear scanty fine scales on it. No specific cause of pityriasis alba has been identified. In this disease, the number of melanocytes declines and melanosomes reduce within melanocytes. Vitamin D exerts its effect via the vitamin D receptor on melanocytes, if intracellular $\mathrm{Ca} 2+$ level decreases, this leads to high levels of reduced thioredoxin this, in turn, inhibit tyrosinase activity with the inhibition of melanin synthesis. In addition, the apoptotic activity of melanocytes reduces by the active form of vitamin D

Aim:

The study aimed to assess the status of vitamin D for patients with pityriasis alba.

Materials and Methods:

44 patient diagnosed with pityriasis alba were enrolled and the second group of 44 controls was involved in our study. Serum levels of circulating $25(\mathrm{OH}) \mathrm{D}$ were measured.

Results:

None of the cases had sufficient serum level; the level ranged between 8.1-27.3 ng/ml. The patients had lower circulating vitamin D levels than controls.

Conclusion:

Our findings in the present study are significant, but further studies with large samples are needed to correlate the extent and severity of pityriasis alba with vitamin D deficiency.
\end{abstract}

Keywords: Pityriasis alba, Melanocyte, Vitamin D, Serum level, Hypopigmentation, Pathogenesis.

\begin{tabular}{|c|c|c|c|}
\hline Article History & Received: February 23, 2019 & Revised: March 27, 2019 & Accepted: April 11, 2019 \\
\hline
\end{tabular}

\section{INTRODUCTION}

Pityriasis alba is a common benign skin disease occurring predominantly among children with less frequency in adolescents. By appearance, it is characterized as fine scales pointing to pityriasis and pale color to alba [1]. Age predominance is between three to 16 years, and most commonly below 12 years. Lesions often occur (a particular site being cheek) on the face [2]. The individual lesions at first appear as round or oval (red or pink and sometimes skin colored) with fine scales and

\footnotetext{
* Address correspondence to this author at the New Baghdad. Sect.709/ street no.40/house no. 2, Baghdad, Iraq; Tel: 009647704355346;

E-mail: wesam.majeed@uomustansiriyah.edu.iq
}

their margins appear indistinct, their number usually ranges from four to 20 and their diameter from one to four $\mathrm{cm}$ [3].

Pityriasis alba is most obvious in individuals with dark pigmented skin and/or following sun exposure [4]. While the hypo-pigmentation seen in pityriasis alba is usually categorized as postinflammatory, the actual pathogenesis is unclear. The number of melanocytes is reduced similar to the number of melanosomes within both melanocytes and keratinocytes [5]. Vitamin D is one of the essential hormones which is synthesized in the skin following the exposure to ultraviolet B via a photochemical process [6]. There are two main forms of vitamin D: Cholecalciferol (vitamin D3) which can be found in 
foods from animal origin and ergocalciferol (vitamin D2) which is present in fungi [7] and the active form of vitamin D, being 1,25-dihydroxyvitamin D3 [1,25(OH) 2 D3], which is a secosteroid that regulates calcium level as well as the process of the metabolism of bone, and controls cell proliferation and differentiation [8]. Vitamin D exerts its effect via a nuclear receptor present primarily in the cells involved in the metabolism of bone; these receptors are also present in other types of cell, in skin as melanocytes, keratinocytes, immunesystem cells and fibroblasts $[9,10]$.

Calcium controls the activity of thioredoxin reductase that is "cytosolic and plasma membrane-associated". If intracellular calcium level decreases, this will lead to high levels of reduced thioredoxin, which, in turn, inhibit tyrosinase activity, finally resulting in the inhibition of melanin synthesis $[11,12]$. The procedure of apoptosis has been reported to removes melanocytes from the skin, this activity which is induced by UVB in both melanocytes and keratinocytes, is reduced by the active form of vitamin $\mathrm{D}$ through the production of interleukin-6 [13 - 15].

The aim of our study was to assess the vitamin D status among patients with pityriasis alba in comparison with the group of controls.

\section{MATERIALS AND METHODS}

This case-control study was carried out at two locations: the outpatient department of AL-Yarmook and Alhussein Thi Qar teaching hospitals from January 2018 to March 2018. 44 patient diagnosed with pityriasis alba were enrolled in this study (none defaulted) along with a second group of patients of age 44, of the same gender and skin type to healthy controls. All patients were carefully examined and the pityriasis alba was diagnosed depending on clinical findings, with the aid of Wood's lamp in suspicious cases. Detailed questionnaire was obtained from all the participants. Various factors including age, gender, and skin photo type were recorded.

Participants with a history of atopic diseases (asthma, allergic rhinitis, and atopic dermatitis), metabolic bone disorders (osteopenia or osteoporosis), disorder of the thyroid gland, kidney or liver disorders, those taking-calcium or vitamin Dcontaining supplements, and those receiving topical or systemic therapy for pityriasis alba within a month prior to the presentation were excluded from this study. Controls were recruited on the same day if possible, to minimize differences (from the relatives of patients if present) and only if not affected by pityriasis alba or any other hypo-pigmented disorders.

Blood samples were taken from both the groups (cases and controls) in the day time after a minimum fasting period of at least 5 hours. Serum levels of circulating $25(\mathrm{OH})$ D were measured [the best indicator of vitamin D status]. The results of vitamin D levels were recorded for both the patients and controls and they assessed to have deficiency: if the level $>20$ $\mathrm{ng} / \mathrm{ml}$; insufficiency, if the level was between $20-29 \mathrm{ng} / \mathrm{ml}$, and sufficiency, if the level was 30-100 $\mathrm{ng} / \mathrm{ml}$ [16]. The Local Ethics Committee approved the study and all the participants were informed about the importance of the status of vitamin D not only for their skin problem, but also for their general health with their consent . The data was statistically analyzed using the chi-squared test to determine whether there was a significant difference in the vitamin D status between the two groups (patients and controls).

\section{RESULTS}

In total, 28 (64\%) males and 16 females (36\%) were involved in our study. In the control group, there were 26 (59\%) males with 18 females (41\%). The mean for the ages of the patient group was $8.18 \pm 3.09$ years and for the other group (control group), it was $8.29 \pm 2.81$ years. The duration of lesions for the cases ranged between three and six weeks. The frequency of site involvement was: face only ( $80 \%)$, face and forearm (11\%), and forearm only (9\%). Regarding the size of the patches of pityriasis alba, $67 \%$ of the patches were between $1-2 \mathrm{~cm}$ in diameter and $30 \%$ were between $2-3 \mathrm{~cm}$ in diameter, while only $3 \%$ were larger than $3 \mathrm{~cm}$ in diameter.

The results of vitamin D assessment among the cases revealed that no one of them had a sufficient level of vitamin D and the level ranged between 8.1-27.3 $\mathrm{ng} / \mathrm{ml}$ (mean: 13.74 $\pm 5.51 \mathrm{ng} / \mathrm{ml}) .36$ patients $(82 \%)$ were deficient and eight patients $(18 \%)$ complaint of insufficiency. In the control group, the level ranged from 14.3 to $37.1 \mathrm{ng} / \mathrm{ml}$ (mean: $21.67 \pm 6.16$ $\mathrm{ng} / \mathrm{ml}) 25$ controls $(56.8 \%)$ had vitamin D deficiency, 12 $(27.3 \%)$ were insufficient, and $7(15.9 \%)$ had sufficiency (Table 1).

\section{DISCUSSION}

Pityriasis alba is a benign condition which causes loss of skin color. Common in childhood and young adulthood, it causes distress due to its appearance on the face. There is no clear racial predominance, although the lesions may be more noticeable in those with darker skin types. Pityriasis alba is not seasonal, although scaling may be worse in the winter (as a result of dry air in homes) and lesions may be more obvious in the spring and summer (as a result of sun exposure and darkening of the surrounding skin) $[17,18]$. Pityriasis alba is thought to represent nonspecific dermatitis with residual postinflammatory hypo-pigmentation [although most commonly occur in individuals with a history of atopy and has been regarded as a manifestation of atopic dermatitis; however, it is also known to occur as non-atopic] as the initial lesions of pityriasis alba are mildly erythematous and erythematous stage may go unnoticed, and the most common presentation is asymptomatic with hypo-pigmented lesions often on the face $[19,20]$. Because of its aesthetic impact, pityriasis alba is a frequent reason for dermatological consultation. Currently, available studies specifically target the explanation of the nature of the disease, therefore, the mechanism through which hypopigmentation occurs and its possible relation to other common problems like vitamin deficiencies remain unclear $[21,22]$. In developing countries, hypo-vitaminosis $\mathrm{D}$ is increasingly found (lifestyle changes in recent decades, with less sun exposure, largely explain this) and several studies now assert the linking increment in the risk of atopic diseases with vitamin D deficiency [23]. Identification of deficiency in specific vitamins may facilitate the development of a new option of therapy. 
Table (1). The differences in values of vitamin D level between patients and controls.

\begin{tabular}{|c|c|c|c|c|c|c|}
\hline $\mathbf{\%}$ & Total No. & $\mathbf{\%}$ & No. of Controls & $\mathbf{\%}$ & No. of Patients & Vitamin D Status \\
\hline 138.8 & 61 & 56.8 & 25 & 82 & 36 & Deficiency \\
\hline 45.3 & 20 & 27.3 & 12 & 18 & 8 & Insufficiency \\
\hline 15.9 & 7 & 15.9 & 7 & 0 & 0 & Sufficiency \\
\hline 200 & 88 & 100 & 44 & 100 & 44 & Total \\
\hline $16.255^{* *}$ & --- & $10.703 * *$ & --- & $13.482 * *$ & --- & Chi-Square \\
\hline
\end{tabular}

$* *(\mathrm{P}<0.01)$

Vitamin D3 exerts a significant effect on melanocytes by increasing tyrosinase activity and stimulates the process of melanogenesis [24]. Vitamin D has been used to treat many dermatoses such as psoriasis and vitiligo for many years $[25$, 26]. In many skin diseases such as alopecia areata, serum vitamin D levels are found to be at low levels [27].

\section{CONCLUSION}

In this study, we measured the serum level of circulating $25(\mathrm{OH}) \mathrm{D}$ [sensitive indicator] to identify the vitamin D status among the cases of pityriasis alba and their matched controls. We identified a significant difference in the values between the two groups, more than $80 \%$ of the patients presented with deficiency and the rest of them had insufficiency [none of the patients had sufficient level of vitamin D]. While in controls, the deficiency noticed in nearly half of patients, $27 \%$ had insufficiency, and $16 \%$ had sufficiency. Another finding in this study is that $87.5 \%$ (14 from 16 patients) of those present with more than five patches of pityriasis alba had deficient serum level of vitamin $\mathrm{D}$, which can lead us to establish a relation between the severity and extent of pityriasis alba with the deficiency of vitamin D status.

Findings in the present study are significant but further studies with large samples are needed to correlate the deficiency of vitamin $\mathrm{D}$ and pityriasis alba.

\section{ETHICS APPROVAL AND CONSENT TO PARTI- CIPATE}

The Local Ethics Committee approved the study.

\section{HUMAN AND ANIMAL RIGHTS}

No Animals were used in this research. All human research procedures followed were in accordance with the ethical standards of the committee responsible for human experimentation (institutional and national), and with the Helsinki Declaration of 1975, as revised in 2013.

\section{CONSENT FOR PUBLICATION}

Informed consent was taken from all the patients when they were enrolled.

\section{FUNDING}

None.

\section{CONFLICT OF INTEREST}

The author declares no conflict of interest, financial or otherwise.

\section{ACKNOWLEDGEMENTS}

Declared none.

\section{REFERENCES}

[1] Jawade SA, Chugh VS, Gohil SK, Mistry AS, Umrigar DD. A clinicoetiological study of dermatoses in pediatric age group in tertiary health care center in south gujarat region. Indian J Dermatol 2015; 60(6): 635.

[http://dx.doi.org/10.4103/0019-5154.169147] [PMID: 26677296]

[2] Vinod S, Singh G, Dash K, Grover S. Clinico epidemiological study of pityriasis alba. Indian J Dermatol Venereol Leprol 2002; 68(6): 338-40.

[PMID: 17656993]

[3] Plensdorf S, Livieratos M, Dada N. Pigmentation disorders: Diagnosis and management. Am Fam Physician 2017; 96(12): 797-804. [PMID: 29431372]

[4] Jean L, Bolognia Julie V, Schaffer Lorenzo Cerroni. Atopic dermatitis. In: Dermatology. 4th. 2018; sect.3: p. 216.

[5] In SI, Yi SW, Kang HY, Lee ES, Sohn S, Kim YC. Clinical and histopathological characteristics of pityriasis alba. Clin Exp Dermatol 2009; 34(5): 591-7.

[http://dx.doi.org/10.1111/j.1365-2230.2008.03038.x] [PMID: 1909 4127]

[6] Lips P. Vitamin D physiology. Prog Biophys Mol Biol 2006; 92(1): 4-8.

[http://dx.doi.org/10.1016/j.pbiomolbio.2006.02.016] [PMID: 1656 3471]

[7] Baeke F, Takiishi T, Korf H, Gysemans C, Mathieu C, Vitamin D Vitamin D: Modulator of the immune system. Curr Opin Pharmacol 2010; 10(4): 482-96.

[http://dx.doi.org/10.1016/j.coph.2010.04.001] [PMID: 20427238]

[8] van Etten E, Mathieu C. Immunoregulation by 1,25-dihydroxyvitamin D3: Basic concepts. J Steroid Biochem Mol Biol 2005; 97(1-2): 93-101.

[http://dx.doi.org/10.1016/j.jsbmb.2005.06.002] [PMID: 16046118]

[9] Wang TT, Tavera-Mendoza LE, Laperriere D, et al. Large-scale in silico and microarray-based identification of direct 1,25dihydroxyvitamin D3 target genes. Mol Endocrinol 2005; 19(11): 2685-95.

[http://dx.doi.org/10.1210/me.2005-0106] [PMID: 16002434]

[10] Prentice A, Goldberg GR, Schoenmakers I. Vitamin D across the lifecycle: Physiology and biomarkers. Am J Clin Nutr 2008; 88(2): 500S-6S.

[http://dx.doi.org/10.1093/ajcn/88.2.500S] [PMID: 18689390]

[11] Parsad D, Pandhi R, Dogra S, Kumar B. Clinical study of repigmentation patterns with different treatment modalities and their correlation with speed and stability of repigmentation in 352 vitiliginous patches. J Am Acad Dermatol 2004; 50: 63-7.

[12] Cicarma E, Mørk C, Porojnicu AC, et al. Influence of narrowband UVB phototherapy on vitamin D and folate status. Exp Dermatol 2010; 19(8): e67-72.

[http://dx.doi.org/10.1111/j.1600-0625.2009.00987.x] [PMID: 1984 9714]

[13] Huang CL, Nordlund JJ, Boissy R. A manifestation of apoptosis. Am J Clin Dermatol 2002; 3: 301-8. 67.

[14] De Haes P, Garmyn M, Degreef H, Vantieghem K, Bouillon R, Segaert S. 1,25-Dihydroxyvitamin D3 inhibits ultraviolet B-induced apoptosis, Jun kinase activation, and interleukin-6 production in primary human keratinocytes. J Cell Biochem 2003; 89(4): 663-73. [http://dx.doi.org/10.1002/jcb.10540] [PMID: 12858333]

[15] Mason RS, Holliday CJ. 1,25-Dihydroxyvitamin D contributes to photoprotection in skin cells.Vitamin D Endocrine System: Structural, 
Biological, Genetic and Clinical Aspects. Riverside: University of California 2000; pp. 605-8.

[16] Hollis BW. Assessment of vitamin D nutritional and hormonal status: What to do and how to measure it. Tissue Int 1996 January; 58(1): 4-5.

[17] Wat H, Dytoc M. Off-label uses of topical vitamin D in dermatology: A systematic review. J Cutan Med Surg 2014;; 18(2): 91-108.

[18] Shah Rajesh. Pityriasis Alba - Not all white spots are Vitiligo M.D.(Hom.) practices in Mumbai, India. 2015 August 25;

[19] Patel AB, Kubba R, Kubba A. Clinicopathological correlation of acquired hypopigmentary disorders. Indian J Dermatol Venereol Leprol 2013; 79(3): 376-82.

[http://dx.doi.org/10.4103/0378-6323.110800] [PMID: 23619442]

[20] Miazek N, Michalek I, Pawlowska-Kisiel M, Olszewska M, Rudnicka L. Pityriasis Alba-Common Disease, Enigmatic Entity: Up-to-Date Review of the Literature. Pediatr Dermatol 2015; 32(6): 786-91. [http://dx.doi.org/10.1111/pde.12683] [PMID: 26477326]

[21] Shen LY, Kenner-Bell BM, Ricketts J, Kundu RV. Ethnic skin: Kids are not just little people. Clin Dermatol 2016; 34(6): 690-7. [http://dx.doi.org/10.1016/j.clindermatol.2016.07.003] [PMID: 2796 8928]

[22] Miazek N, Michalek I, Pawlowska-Kisiel M, Olszewska M, Rudnicka
L. Pityriasis alba-common disease, enigmatic entity: Up-to-date review of the literature. Pediatr Dermatol 2015; 32(6): 786-91. [http://dx.doi.org/10.1111/pde.12683] [PMID: 26477326]

[23] Mesquita KdeC, Igreja AC, Costa IM. Atopic dermatitis and vitamin D: facts and controversies. An Bras Dermatol 2013; 88(6): 945-53. [http://dx.doi.org/10.1590/abd1806-4841.20132660] [PMID: 2447 4104]

[24] Adorini L, Penna G. Control of autoimmune diseases by the vitamin D endocrine system. Nat Clin Pract Rheumatol 2008; 4(8): 404-12. [http://dx.doi.org/10.1038/ncprheum0855] [PMID: 18594491]

[25] Ustun I, Seraslan G, Gokce C, et al. Investigation of vitamin D levels in patients with vitiligo vulgaris. Acta Dermatovenerol Croat 2014; 22(2): 110-3.

[PMID: 25102796]

[26] Birlea SA, Costin GE, Norris DA. New insights on therapy with vitamin D analogs targeting the intracellular pathways that control repigmentation in human vitiligo. Med Res Rev 2009; 29(3): 514-46. [http://dx.doi.org/10.1002/med.20146] [PMID: 19241402]

[27] Aksu Cerman A, Sarikaya Solak S, Kivanc Altunay I. Vitamin D deficiency in alopecia areata. Br J Dermatol 2014; 170(6): 1299-304. [http://dx.doi.org/10.1111/bjd.12980] [PMID: 24655364]

\section{C) 2019 Kattoof and Kawen.}

This is an open access article distributed under the terms of the Creative Commons Attribution 4.0 International Public License (CC-BY 4.0), a copy of which is available at: https://creativecommons.org/licenses/by/4.0/legalcode. This license permits unrestricted use, distribution, and reproduction in any medium, provided the original author and source are credited. 